\title{
RESULTS OF SPINAL TUMORS SURGERY
}

\author{
T. Avramov, G. Kyuchukov, I. Kiryakov, N. Obreshkov, D. Handjiev, R. Nedelko \\ Clinic of Neurosurgery and Neurology, St. Anna Hospital, Varna \\ Department of Neurosurgery, Eye diseases and ENT, \\ Medical University „Prof. P. Stoyanov”, Varna, Bulgaria
}

\section{SUMMARY}

The clinical files of 122 operated patients in our Clinic of Neurosurgery St. Anna Hospital - Varna during 5-year period were retrospectively reviewed. 68 of them had significant episodes of radicular pain, 100 - motor deficit and 62 - bladder disfunction. X-ray, bone CT and MRT were performed in 56, 23, 79 patients, respectively. MRI effectively showed intra- extravertebral mass lesions. Overall treatment led to improvements in pain and motor deficit of $45 \%$ of patients. Radicular pain, neurological deficit, infection, venous thrombosis, pneumonia and other complications before and after surgery are the major problems. The mortality rate in our series is 7,3\%. It's needed to determine the optimal timing of treatment strategies chemotherapy, radiation therapy and especially of surgery.

Key words: spinal tumors, spinal cord compression, surgical treatment, laminectomy, transpedicular fixation, postoperative complications.

\section{INTRODUCTION}

Treatment of spine and spinal cord tumors is complex and a multidisciplinary approach is required. Contemporary treatment include surgery, radiation therapy and chemotherapy. Outcome is dependent upon a number of factors. These factors are: the site of tumor compression within the spinal canal, the histological characteristics of the tumors, the tempo of neurologic progression and initial response to corticosteroid therapy, patient age, comorbidity, tumor extension, envolvement of neighbour structures and organs, etc. spinal cord tumors constitute $2 \%$ of all tumors and 1-3\% of tumors of central nervous system. Approximately $25 \%$ of spinal cord tumors are extramedullary (25\% neurinoma and 20\% meningeoma); primary intramedullary tumors comprise $10-15 \%$ and metastatic tumors 40-80\%(1-3, 7-9, 12, 15, 17, 23-27, 33-39). Ambulatory patients who received surgery (decompression and stabilization of the spine when needed), are more likely to show improvement $(3,6,9,12-14,17-21)$. Bilsky and Hufana reported improvement in $90 \%$ of cases with extramedullary benign tumors when totally extirpated. On the other hand for the spinal metastases the outlook remains poor, in these cases surgery is palliative. Postoperative mortality have varied from $8-11 \%(3,10,17,21,25)$. The major factors influencing postoperative complications include deficits and comorbidity. Postoperative complications incidence as per Bilsky varies from 10 to $52 \%$ and the most frequent are the venous thrombembolism, infarct, infection, bronchopneumonia, failure of the stabilization and pain. The aim of this study is to analyze the data gathered, for the patients with spine and spinal cord tumors, treated in our clinic, in order to make the necessary conclusions for more effective treatment and prevention of intra and postoperative complications.

\section{METHODS}

The records of 122 patients with spine and spinal cord tumors, who received surgery in our clinic for the period 2004-2008 were retrospectively reviewed.

Characteristics of patients:

\begin{tabular}{|l|c|}
\hline \multicolumn{1}{|l|}{ Variable } & Number \\
\hline Age (in years) & 1 \\
\hline$<20$ & 11 \\
\hline $21-40$ & 58 \\
\hline $41-60$ & 52 \\
\hline $61-80$ & \\
\hline \multicolumn{2}{|l}{} \\
\hline Sex & 66 \\
\hline Male & 56 \\
\hline
\end{tabular}

Presenting symptom

\begin{tabular}{|l|c|}
\hline Pain & 68 \\
\hline Numbness & 105 \\
\hline Paraparesis & 37 \\
\hline Paraplegia & 44 \\
\hline
\end{tabular}




\begin{tabular}{|l|c|}
\hline Quadriparesis & 11 \\
\hline Cauda equine syndrome & 7 \\
\hline Brown-Sequard syndrome & 1 \\
\hline Bowel or Bladder problem & 62 \\
\hline
\end{tabular}

Neuroimaging

\begin{tabular}{|l|l|}
\hline Plain X-ray & 56 \\
\hline CT scan & 23 \\
\hline MRI & 79 \\
\hline Myelography & 23 \\
\hline
\end{tabular}

\section{Comorbidity}

\begin{tabular}{|l|c|}
\hline Hypertension & 62 \\
\hline Heart failure & 50 \\
\hline Diabetes & 12 \\
\hline COPD & 13 \\
\hline Lung carcinoma & 19 \\
\hline Bowel adenocarcinoma & 8 \\
\hline Breast carcinoma & 6 \\
\hline Prostate & 5 \\
\hline Cervical carcinoma & 4 \\
\hline Kidney carcinoma & 1 \\
\hline Thyroid gland carcinoma & 1 \\
\hline
\end{tabular}

The aim of surgery was decompression of the spinal cord, total removal of the tumor when possible and spinal stabilization when needed. The surgery performed is outlined below:

\begin{tabular}{|l|c|}
\hline Hemi or laminectomy & 112 \\
\hline Arthropediculotomy & 6 \\
\hline Spondylectomy & 4 \\
\hline Metal instrumentation a modo Luquez & 27 \\
\hline Transpedicular stabilization & 16 \\
\hline Anterior vertebrodesis & 4 \\
\hline Vertebroplasty & 3 \\
\hline Without stabilization & 72 \\
\hline
\end{tabular}

\section{RESULTS}

Many factors have influenced the outcome of surgical treatment. The most important are the histological characteristics of tumor, spinal segment affected and the degree of decompression.

Spinal level
\begin{tabular}{|l|c|}
\hline C2 - C5 & 7 \\
\hline C6 - C7 & 6 \\
\hline Th1 - Th5 & 11 \\
\hline Th6 - Th8 & 30 \\
\hline Th9 - Th12 & 34 \\
\hline L1 - L5 & 34 \\
\hline
\end{tabular}

Nature
\begin{tabular}{|l|c|}
\hline Metastases & 51 \\
\hline Myeloma & 15 \\
\hline Lymphoma & 7 \\
\hline Meningeoma & 12 \\
\hline Neurinoma & 3 \\
\hline Neurofibroma & 6 \\
\hline Cavernous hemangioma & 5 \\
\hline Lypoma & 2 \\
\hline Fibrolyposarcoma & 4 \\
\hline Mesotelioma & 1 \\
\hline Others & 14 \\
\hline
\end{tabular}

Satisfactory postoperative outcome corresponds with the degree of decompression- total removal of meningeomas or neurinomas leads to full recovery, but decompression in cases of primary intramedullary tumors and metastases is palliative and accompanied with complications.

Patients onset of improvement

\begin{tabular}{|l|c|}
\hline Immediate & 8 \\
\hline With improvement at discharge & 47 \\
\hline No improvement at discharge & 53 \\
\hline Worsened & 5 \\
\hline Exitus letalis & 9 \\
\hline Pulmonary embolism & 5 \\
\hline Heart failure & 2 \\
\hline Bronchopneumonia & 2 \\
\hline
\end{tabular}

The most frequent difficulties encountered during surgery were the profuse bleeding, difficulties when undergoing spinal instrumentation due to tumor infiltration of neighbouring levels or osteoporosis. Postoperative complications include: CSF leakage- 2 cases, woud infection5 , surgical site haematoma- 3 , bronchopneumonia- 12 , renal failure- 5 . 


\section{DISCUSSION}

The extent of tumor resection and decompression correlates directly with a good outcome. The period from the onset of first neurological symptoms till the diagnosis in $90 \%$ of our cases was $2-6$ weeks. This period is long enough for the development of undesired factors influencing the outcome after surgery. The same was reported in the literature by Bauer, Brotchi, Dunn, Klekamp. That's why, from 27 cases of total tumor removal, only in 8 cases we registered full recovery. The extent of excision either incomplete or biopsy was found to positively correlate with postoperative improvement; 40 cases in our study. In the last cases the improvement was temporary but we didn't realize to record the period free of complains and the development of the disease. This is because in our country we don't have yet a developed multidisciplinary approach and follow- up tools for patients suffering of this pathology.

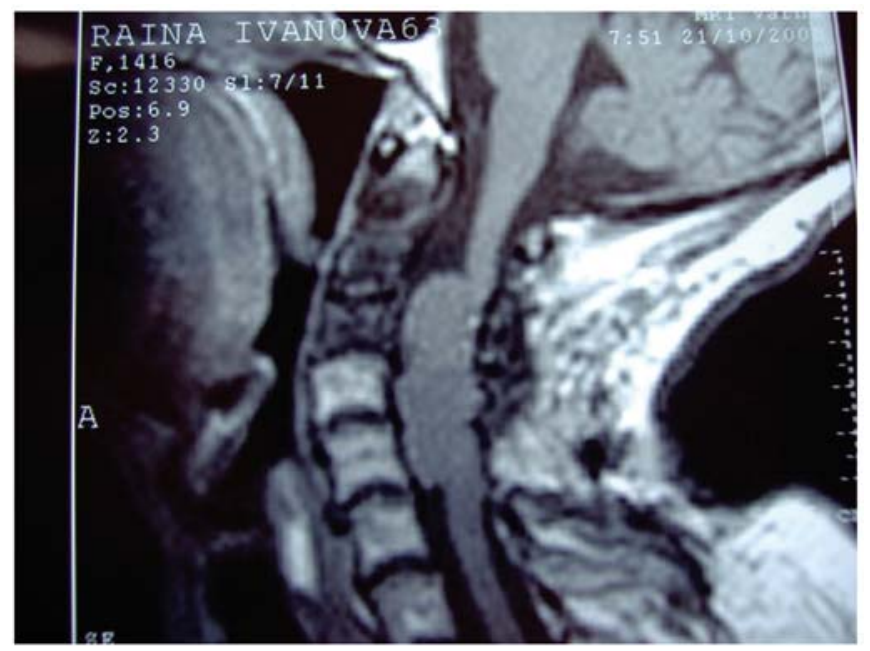

Patients with relapsed meningeom at C3 and compression mielona.
$90,5 \%$ of patients discharged without improvement were with spinal metastases. These data are approximately the same with the statistics reported from most of the authors. Postoperative complications vary $10-52 \%(9,12,15,17,21$, 23-27, 33-39). Different causes were reported such as: bronchopneumonia, embolism, heart failure, surgical site haematoma, failure of stabilization, infections, CSF leakage etc. $32 \%$ of our cases experienced postoperative complications. Wide range of mortality rate was reported from different authors- Cohen \& Allen report a mortality rate $0-3 \%$, Bilsky $13 \%$ and in our study $7,3 \%$

Most of factors influencing surgical treatment and the outcome are well known. That's why through early diagnosis and proper treatment (surgery, radiation and chemotherapy), the complications can be avoided or at least minimized.

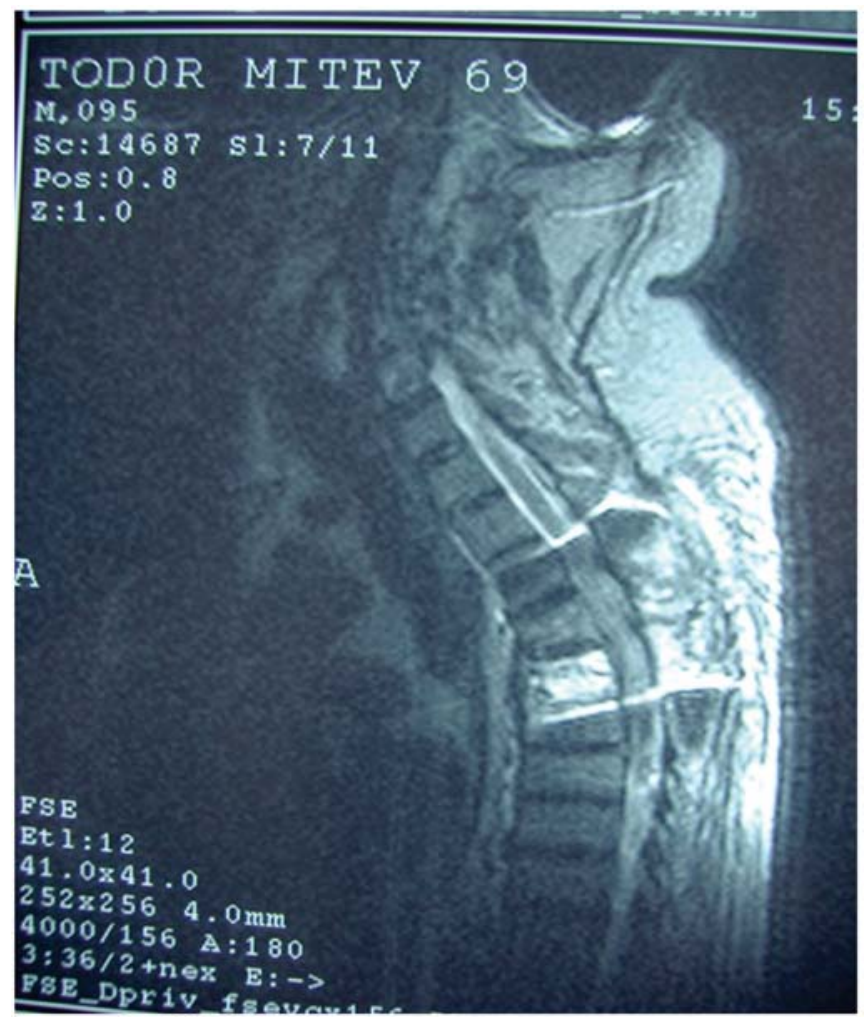

Patient with metastasis in the body of Th7 


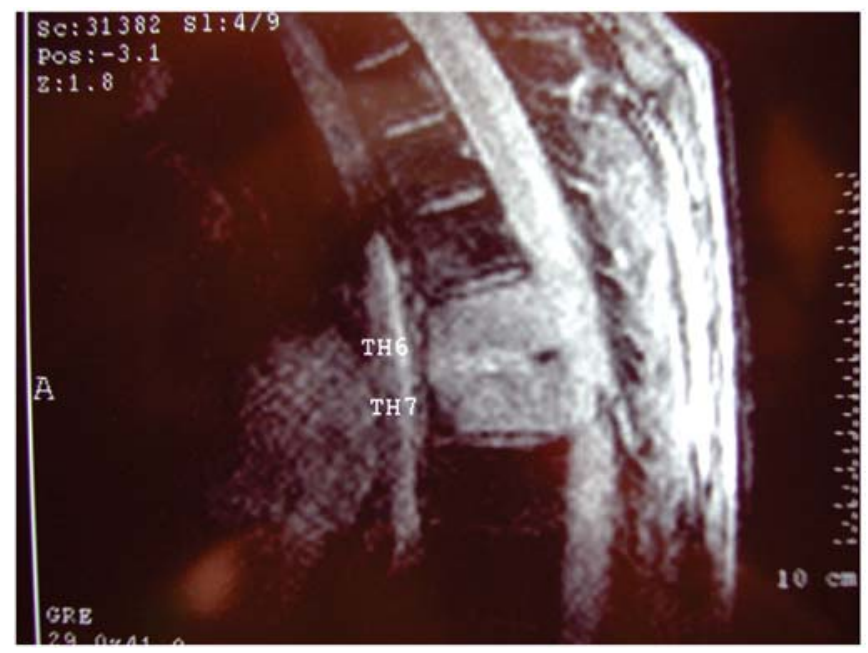

Patients with bone metastases in the vertebral bodies of Th6 and Th7

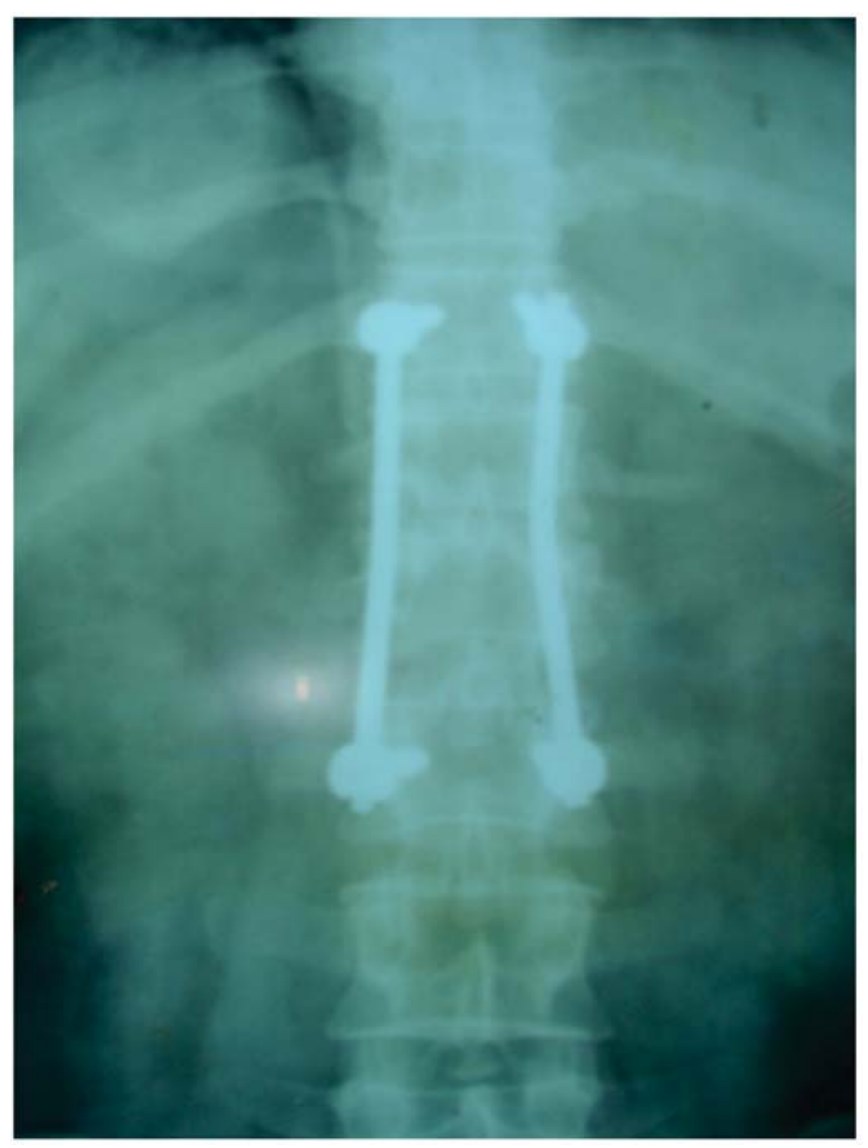

Ro columns transpedicular a patient with a pathological fracture due to stabilization of the bodies of L1 and L2.

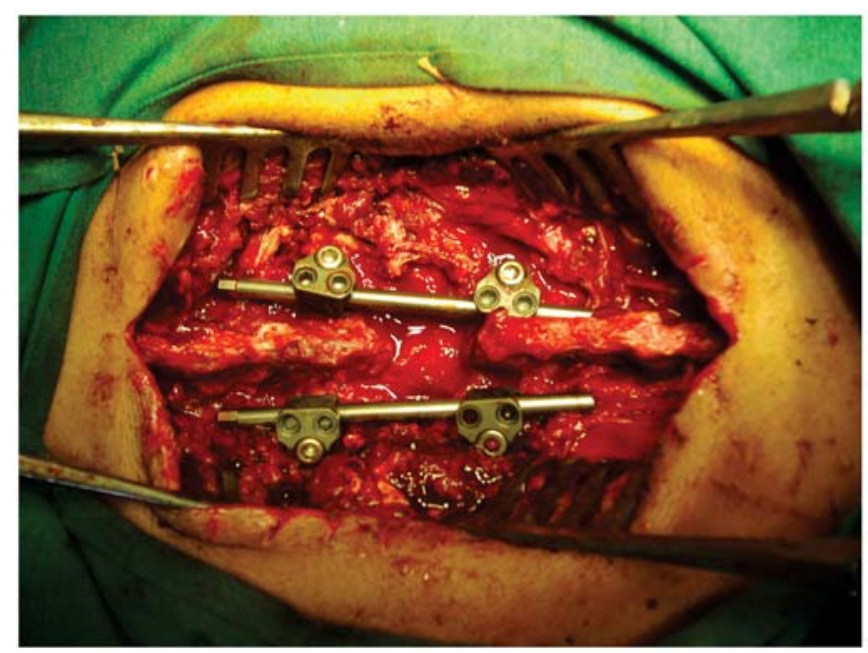

Transpedicular stabilization in the lumbar and laminektomiya after total excision of tumor ekstraduralen 


\section{REFERENCES:}

1. Angevine PD, McCormack PC:Spinal cord ependymomas. Operative Techniques Neurosurg 2003, 6:9-14

2. Bauer HCF, Wedin R: Survival after surgery for spinal and extremity metastases: prognostication of 241 patients. Acta Orthoped Scand 1995, 66:143-146(Medline)

3. Bilsky MH, Lis E, Raizer J, Lee h, Boland P: The diagnosis and treatment of metastatic spinal tumors. The Oncologist, 1999, 4(6):459-469

4. Bridwell K, Jenny A, Saul T et al: Posterior segmental spinal instrumentation with posterolateral decompression and debulking for metastatic thoracic and lumbar spine disease. Spine 1998, 13:13831394

5. Brotchi J : Intrinsic spinal cord tumor resection. Neurosurgery 2002, 50:1059-1063

6. Brotchi J, Lefranc F : Current management of spinal cord tumors. Contemp Neurosurg 1999, 21:1-8

7. Brown L Middleton G, Macvicar Ad et al: Vertebral metastases: changes on treatment and correlation with response to therapy.Clin Radiol 1998, 53: 493-501

8. Byrne TN: Spinal cord compression from epidural metastases. N Engl J Med 1992, 327: 614-619(Medline)

9. CahillDW, Kumar R: Palliative subtotal vertebrectomy with anterior and posterior reconstruction via a single posterior approach.J Neurosurg 1999, 90: 42-47

10. Cohen AR, Wisoff JH, Allen JC, Epstein F: Malignant astrocytomas of the spinal cord. J Neurosurg 1989, 70: 50-54

11. Constantini S, Miller DC, Allen JC, Rorke LB, Freed D, Epstein JF: Radical excision of intramedullary spinal cord tumors: Surgical morbidity and long term follow-up evaluation in 164 children and young adults. J Neurosurg, Spine: 2000, 93:183-193

12. Cooper P, Errico T, Martin R et al: A systematic approach to spinal reconstruction after anterior decompression for neoplastic disease of the thoracic and lumbar spine. Neurosurgery 1993, 32: 18(Medline)

13. DunnJr RC, Kelly WA, Wohns RNW et al:Spinal epidural neoplasia. A 15-year review of the results of surgical therapy. J Neurosurg 1980, 52; 4751(Medline)

14. Epstein FJ, Farmer JP, Freed D: Adult intramedullary astrocytomas of the spinal cord. J Neurosurg 1992, 77: 355-359

15. Gilbert RW, Kim JH, Posner JB: Epidural spinal cord compression from metastatic tumor : diagnosis and treatment. Ann Neurol 1978, 3: 40-51 (Medline)

16. Gokaslan ZL, York JE et al: Transthoracic vertebrectomy for metastatic spinal tumors. J Neurosurg 1998, 89: 599609

17. Han IH, Kuh SU, Chin DK, Jin $\mathrm{BH}$, Cho YE: Surgical treatment of primary spinal tumors in the medullaris. J Kor Neurosurg Ass, 2008, 44(2): 72-77

18. Holman PJ, Suki D, McCutcheon I, Wolinsky J-P, Rhines LD et al: Surgical management of metastatic disease of the lumbar spine: experience with 139 patients. J Neurosurg: Spine, 2005, 2(5): 550-563

19. Houten JK, Cooper PR: Spinal cord astrocytomas, presentacion, management and outcome, J Neurooncol 2000, 47:219224

20. Hoshimaru M, Koyama T, Hashimoto $\mathrm{N}$ et al: Results of microsurgcical treatment for intramedullary spinal cord ependymomas. Analysis of 36 cases. Neurosurgery 1999, 44:264-269

21. Hufana V, Tan JSH, Tan KK: Microsurgical treatment for spinal tumors. Surg Med J, 2005, 46(2):74-77

22. Isaacson SR: Radiation therapy and the management of intramedullary spinal cord tumors. J Neurooncology 2000, 47:231-238

23. Klekamp J, Samii H: Surgical results for spinal metastases. Acta Neurochir (Wien) 1998, 140: 957967(Medline)

24. Klimo P Jr, Kestle JR, Schmidt MH: Treatment of metastatic spinal epidural disease: a review of the literature. Neurosurg Focus, 2003, 15(5): 1-9

25. Лившиц $\mathrm{AB}$ : Хирургия спинного мозга. Москва, 1990, стр.258-280

26. Maranzano E, Latini P: Effectiveness of radiation therapy without surgery in metastatic spinal cord compression: final results from a prospective trial.Int J Radiat Oncol Biol Phys 1995, 32: 959-967(Medline)

27. McCormick PC, Stein BM: Spinal cord tumors in adults.In Youmans JR ,ed Neurological Surgery. Philadelphia. WB Saunders, 1998, 3102-3122

28. Miller DJ, McCutcheon IE: Hemangioblastomas and other uncommon intramedullary tumors. J Neurooncol 2000, 47:253-270

29. North RB, LaRocca VR, Schwartz J, North CA et al : Surgical management of spinal metastases; Analysis of prognostic factors during a 10-year experience. J Neurosurg: Spine, 2005, 2(5): 564-573

30. Perrin RG,McBroom RJ: Spinal fixation after anterior decompression for symptomatic spinal metastases. Neurosurgery 1998, 22:324-327

31. Sama AA, Girardi FP, Cammisa FP: Spinal Tumors.eMedicine Orthopedic Text Book, 2008, 3-12

32. Sanderson SP, Cooper PR: Intramedullary spinal cord astrocytomas. Operative Techniques Neurosurgery 2003, 6:1-23

33. Schwartz TH, McCormick PC : Intramedullary spinal cord tumors.Special issue. J Neurooncol 2000, 47: 187-317

34. Schwartz TH, McCormick PC : Intramedullary ependymomas: Clinical presentation, surgical treatment, strategies and prognosis. J Neurooncol 2000, 47:211218

35. Sciubba DM, Petteys RJ, GarcesAmbrossi GL, Noggle JC, McGirt MJ et al: Diagnosis and management of sacral tumors. J Neurosurg: Spine ,2009, 10(3) : 244-256

36. Solero CL, Formari M, Giombini S, Lasio G, Oliveri G, Cimino C et al: Spinal meningeomas: review of 174 operated cases. Neurosurgery 1989, 25: 153-160

37. Sundaresan N, Digiacinto GV, Hughes JE et al: Treatment of neoplastic spinal cord compression: results of prospective study. Neurosurgery 1991, 29: 645-650

38. Sundaresan N, Steinberger AA, Moore $\mathrm{F}$ et al : Indications and results of combined anterior-posterior approaches for spine tumor surgery.J Neurosurg 1996, $85: 438-446$

39. Taricco MA, Guirado VMP, Fontes RBV, Piese JPP: Surgical treatment of primary intramedullary spinal cord tumors in adult patients. Arq. Neuro Psiquiatr. 2008, vol 66, N1: 1-8

\section{Address for correspondence:}

Tony Avramov

Department of Neurosurgery, St Anna Hospital, MU „Prof. P. Stoyanov”, Varna, Bulgaria; E-mail: toniavram@abv.bg 